\title{
PERSPECTIVES OF BIOREMEDIATION AS A PANACEA FOR ECOLOGICAL POLLUTION
}

\author{
O. O. ALONGE, T. O. FAMAKINWA AND M. M. MATOUKE
}

(Received 29 September 2016; Revision Accepted 3 May 2017)

\begin{abstract}
:
Analyzing the prospects of bioremediation methods and technologies as a potential clean up solution and remedy to the current environmental pollution problems facing the world today. Due to the significant rise in the number of manufacturing/ heavy industries, increase in the volume of crude oil drilling, and refining and transportation the area of contaminated land and water by heavy metals and petroleum hydrocarbon has consequently increased has a result of accidents, spills, dumping, etc., posing serious risk to human health and livelihood, as well disrupting the ecosystem and climate.

Bioremediation methods and technologies can mostly be combined and carried out in a multi stage process to get best results. For instance, in the event of an oil spill the initial Raskin, Ensley, 2000; Tyagi, et al, 2010; Alonge, 2016), as opposed to previous harmful and environmentally degrading clean up procedure should involve the physical I mechanical removal of excess crude oil from the surface of the contaminated medium, by the use of hydraulic pumps, skimmers, boomers, surfactant's etc. At the second stage a suitable technique of microbial bioremediation can be applied, depending on the prevailing conditions. Lastly phytoremediation techniques can be applied at the final stages to complete the cleanup and restoration of the contaminated soil or water medium.
\end{abstract}

KEYWORDS: Bioremediation, environmental pollution, phytoremediation, rhizosphere, petroleum hydrocarbon, heavy metals.

\section{INTRODUCTION}

The problem of environmental pollution especially by heavy metal contamination, and crude oil spill is one of the biggest challenges facing the modern world today (Dushenkov, et al, 1995; Vidali, 2001; Alvarez, Illman, 2006; Alonge, Vasenev, 2016).

According to estimates the total amount of petroleum hydrocarbon spilled into the oceans through human activities is estimated to range from about 0.71.7 million tons annually (science.jrank.org, 2017).In Nigeria the Federal Ministry of Environment estimates that the quantity of oil spilled over 50 years was a least 9-13 million barrels, which is equivalent to 50 Exxon Valdez spills (FME et al, 2006) leading to environmental degradation, climate change, loss of farmland for agricultural purposes, loss of livelihood to fishermen, as well as contributing to various health problems (Alonge, 2016).

Therefore the need to develop an environmentally safe and cost-effective technology for the cleaning up and restoration of contaminated soil and water is especially vital (Dushenkov, et al, 1995; methods of incineration, landfill, and the use of toxic chemical dispersant, such as Corexit, to clean up oil pollution (Graham, et al, 2016). Corexit has been known to potentially harm the environment, wildlife, and human health (US Environmental Protection Agency, 2014).
Currently the most promising cleanup technology of contaminated soils and water is considered to be bioremediation (Dua, et al, 2002; Alvarez, Illman, 2006; Alonge, 2016). Bioremediation is the application of specialized techniques designed to biodegrade toxic contaminants in soil and water, using organisms such as bacteria, fungi, and plants to breakdown contaminants such as petroleum hydrocarbon, heavy metals, pesticides, radionuclides, etc., in a medium, and transform them into harmless byproducts (Vidali, 2001; Dua, et al, 2002; Alvarez, Illman, 2006; Alonge, Vasenev, 2016).

Bioremediation could be of two types depending on the organism used as follows: Microbial bioremediation - involves the use of microorganisms such as bacteria (Pseudomonas, Arthrobacter, Azotobacter, Bacillus, Rhodococcus; Streptomyces, etc); and fungi (Aspergillus, Candida, Fusarium, Penicillium, etc) to decompose contaminants in a medium (Vidali, 2001; Dua, et al, 2002; Alvarez, Illman, 2006; Tyagi, et al, 2010; Alonge, Vasenev, 2016).

Phytoremediation: Involves the use of some plants species such as mustard plants (Brassica sp.), alpine pennycress (Thlaspi sp.), hemp (Cannabis sp.), sunflower (Helianthus sp.), water hyacinth (Eichhornia $s p$.), etc., to clean up contaminated mediums of soil and water by extracting toxic compounds from a

O. O. Alonge, Department of Biological Sciences, Baze University, Abuja, Nigeria.

T. O. Famakinwa, Department of Biological Sciences, Baze University, Abuja, Nigeria.

M. M. Matouke, Department of Biological Sciences, Baze University, Abuja, Nigeria. 
contaminated medium, and accumulating the contaminants in plant biomass (Blaylock, et al, 1995; Binet, et al, 2000; Raskin, Ensley, 2000).

\section{BIOREMEDIATION METHODS AND TECHNOLOGIES}

There are two basic methods of approach to the bioremediation of contaminated soil and water, these are: in-situ (on-site), \& ex-situ (off-site) bioremediation (Vidali, 2001; Dua, et al, 2002; Alvarez, Illman, 2006):

1. In situ Bioremediation: involves the onsite treatment and cleanup of contaminated medium, without excavation (Vidali, 2001).

2. Ex situ Bioremediation: involves the excavation and transportation of contaminated medium for off-site treatment and clean up (Vidali, 2001).

These methods can be applied for both microbial bioremediation and phytoremediation.

In Situ Microbial Bioremediation: There are four basic microbial bioremediation techniques used for the onsite treatment and cleanup of contaminated soil and water, each with its own peculiarities and advantages as follows:

i. Natural Attenuation: is bioremediation that occurs without human intervention other than monitoring. This process relies on natural environmental conditions and the metabolic activities of microorganisms / organisms involved in the biodegradation process. This method unlike other methods of in-situ bioremediation is slow, and takes many years to completely restore the contaminated medium (Vidali, 2001; Dua, et al, 2002; Alvarez, Illman, 2006).

ii. Biostimulation: is bioremediation that involves the stimulation and utilization of the indigenous microbial populations in contaminated soil to biodegrade contaminants. For the success of this technique it is vital to create optimal conditions for the microorganisms in the contaminated medium, by improving percolation, aeration, $\mathrm{pH}$ balance, moisture, and the addition of nutrients to activate and accelerate the decomposition of contaminants (Vidali; 2001; Alvarez, Illman, 2006; Tyagi, et al, 2010).

iii. Bioaugmentation: in contrast to biostimulation, bioaugmentation involves the introduction / inoculation of specially selected / genetically engineered strains of microorganisms (Biopreparations), particularly adapted to the contaminated medium, and capable of detoxifying specific contaminants (Tyagi, et al, 2010; Alonge, 2016).

The introduced microorganism could be single specie or a consortium of microorganisms, and it is particularly important to make sure that the inoculation of these microorganisms does not lead to microbial antagonism and competition with the indigenous microbial community of the contaminated medium (Stankevich, 2002).

Similar to biostimulation, the technique of bioaugmentation also ensures the creation of conducive and optimal conditions for the acceleration of the process of bioremediation by microorganisms (Tyagi, et al, 2010; Alonge, 2016).

iv. Bioventing: is a technique of in situ bioremediation that makes use of the indigenous microbial population to decompose contaminants adsorbed in the soil and groundwater. In contrast to biostimulation and bioaugmentation, in bioventing the oxygen content is regulated by inducing air into the lower regions of the soil profile using vents, and taking out waste gases, to ensure the process of bioremediation takes place under aerobic conditions (Dupoint; Hinche, 1991).

Ex situ Microbial Bioremediation: after excavation and transportation of the contaminated medium to an off-site location for restoration, the following techniques can be used to clean-up the contaminated medium:

i. Land farming: is a technique that involves the excavation of the contaminated upper soil layer $(10-40 \mathrm{~cm})$ and spread over land or on a layer of polyethylene material to facilitate the biodegradation process by both indigenous and I or inoculated microorganisms. Microbial activity of the contaminated medium is stimulated by optimizing moisture content, nutrient availability, as well as regulating temperature and $\mathrm{pH}$ of the medium. Percolation and aeration of the soil is done by regular tilling, which also facilitates the chemical and physical processes of contaminant degradation (Vidali, 2001; Dua, et al, 2002).

ii. Composting: is an ex situ bioremediation technique that involves mixing contaminated soil with nontoxic organic compounds, such as animal droppings (manure), plant leaves, saw dust, etc., and pilling into a heap to facilitate the decomposition process (Vidali, 2001). The organic matter serves as a source of nutrient and energy for the microbial community in the combined heap. The temperature, moisture and air contents are maintained and controlled regularly by turning the mixture and adding of water.

iii. Biopiles: is an ex situ bioremediation technique that involves piling contaminated soil into a compost heap (bio heap) and enclosing in a treatment bed with polyethylene material to prevent evaporation, surface runoff, and volatile emissions.

In this technique temperature, moisture and oxygen contents, $\mathrm{pH}$, and nutrient availability are closely controlled using pump or air injection blower system to stimulate microbial activity and accelerate the decomposition process (Hinchee, Miller, Dupont, 1991; Vidali, 2001).

iv. Bioreactors (slurry bioreactor): is a technique of ex-situ bioremediation using automated 
containment system, where the treatment of contaminated soil and water is isolated and controlled, to enhance microbial activity and accelerate the bioremediation process (RoblesGonzález et al, 2008).

Phytoremediation: depending on the scale and type of contaminant, topography as well as the contaminated medium involved, phytoremediation can be carried out both in situ and ex situ using suitable plants best adapted to the prevailing environmental conditions. Techniques of phytoremediation can broadly be classified in to the following:

i. Phytoaccumulation (phytoextraction): is the use of plants that can bind and extract toxic elements from the soil and water, and accumulate them in plants biomass. For example, mustard plant can be used to remove silver, chromium, cobalt, lead, zinc, etc., from contaminated medium (Blaylock, et al, 1995; Schnoor, 1997; Raskin, Ensley, 2000).

ii. Phytotransformation (Phytodegradation): is phytoremediation whereby plants such as hybrid poplar trees absorb contaminants from soil and groundwater and subsequently transform / degrade them to simpler, more stable, less toxic, forms (Blaylock, et al, 1995; Burken, Schnoor, 1997).

These plants transform the compounds either by metabolic processes within the plant; or by the actions of enzymes, produced by the plant. For example trichloroethylene (TCE) is transformed to trichloroethanol, trichloroacetic acid, and dichloroacetic acid by hybrid poplar trees (Newman, et al, 1997).

iii. Phytostabilization: is a phytoremediation technology that involves the immobilization of toxic contaminants (heavy metals) in the soil through sorption into / onto the plant by the roots. For instance exavalent chromium can be immobilized to non-carcinogenic trivalent chromium (Blaylock, et al, 1995; Schnoor, 1997; Raskin, Ensley, 2000).

iv. Rhizodegradation

(Phytostimulation): involves the biodegradation of contaminants by the combined action of microorganisms that form a symbiotic interaction in the rhizosphere of some phytoremediation capable plants (Binet, et al, 2000).

Microorganisms such as fungi and bacteria use the contaminant as a source of energy and substrate, converting them into less harmful by products, which are easily absorbable by plants. This technique is also known as phytostimulation because the plant provides additional nutrients to enhance microbial activity. (Schnoor, 1997; Wang, et al, 2013).

v. Rhizofiltration: is a water renovation technique that uses plant roots to absorb, concentrate and remove toxic substances from surface or groundwater. E.g., Indian mustard, sunflower, etc., can be used to filter and extract toxic metals such as $\mathrm{Cu}^{2+}, \mathrm{Cd}^{2+}, \mathrm{Cr}^{6+}, \mathrm{Pb}^{2+}, \mathrm{Ni}^{2+}, \mathrm{Zn}$ ${ }^{2+}$, from aqueous solutions (Dushenkov, et al, 1995; Schnoor, 1997; Raskin, Ensley, 2000).

vi. Phytovolatization: is a phytoremediation process whereby plants such as Brassica $s p$. absorb organic contaminants from the soil modify into less harmful byproducts and release into the atmosphere in volatile form during transpiration (evapo-transpiration). For example, Selenium (Se) has been shown to be partially volatized by Brassica sp. from contaminated soil (Schnoor, 1997).

In summary phytoremediation methods and technologies are cost effective, ecologically safe and efficient. However the efficacy of these technologies is limited to the surface area and depths of the plants roots; relatively slow plant growth, which could also be inhibited by the toxic contaminants in the contaminated medium (Alonge, 2016). Therefore phytoremediation can be applied at the final stage of bioremediation process.

\section{FACTORS THAT AFFECT BIOREMEDIATION}

The major factors that influence the rate of bioremediation process, and determine the application of any of the various bioremediation methods and technologies are the: type and concentration of the contaminant; scale and depth of contamination; topography; prevailing climatic conditions; hydrogeological conditions; source of contamination; technical and financial capability; type of organism / microorganisms involved; as well as nutrient availability (Schnoor, 1997; Vidali, 2001; Dua, et al, 2002; Tyagi, da Fonseca, de Carvalho, 2010).

\section{CONCLUSION}

Bioremediation methods and technologies can mostly be combined and carried out in a multi stage process to get best results. For instance, in the event of an oil spill the initial clean up procedure should involve the physical (mechanical) removal of excess crude oil from the surface of the contaminated medium, by the use of hydraulic pumps, skimmers, boomers, surfactant's etc. At the second stage a suitable techniques of microbial bioremediation can be applied, depending on the prevailing conditions. Lastly phytoremediation techniques can be applied at the final stages to complete the cleanup and restoration of the contaminated medium.

Bioremediation is a simple, highly specific natural process that is environmentally safe, widely accepted and less expensive than conventional methods of excavation, landfills, incineration etc. It does not transfer contaminants from one medium to the other; it eliminates waste permanently and proffers long-term solutions.

Like every other technology bioremediation has its limitations, for example, it generates greenhouse gases in some cases and forms more persistent / toxic compounds (Vidali, 2001; Dua, Singh, Sethunathan, 2002; Tyagi, da Fonseca, de Carvalho, 2010). 
However the advantages of the bioremediation techniques and technologies far outweigh the disadvantages and these bioremediation technologies can be perfected to significantly speed up the rate of degradation, reduce greenhouse emissions, and minimize surface runoff. Therefore bioremediation can be adopted as a clean-up technology and remedy to the environmental pollution challenges in our present day.

\section{REFERENCES}

Alonge, O. O and Vasenev, I. I., 2016. Ecological evaluation of the effects of different soil moisture conditions on the efficacy of Pseudomin in the bioremediation of diesel fuel contaminated derno-podzoluivisolic soil. International Journal of Advanced Biotechnology Research, 6, (2): 232-235.

Alonge, O. O., 2016. Comparative evaluation of the efficacy of Pseudomonas putida in the bioremediation of diesel fuel contaminated derno-podzoluivisolic soil of different horizons. Global Journal of Pure and Applied Sciences, 22, 129-133.

Alonge, O. O., 2016. Analysis of the phytotoxic effects of diesel fuel contaminated derno-podzoluivisolic soils on plants and the impact of biopreparation pseudomin in detoxification under different soil moisture conditions. International Journal of Advanced Biotechnology Research, 6(3): 370372.

Alvarez, P. J. J and IIIman, W. A., 2006. Bioremediation and Natural Attenuation, Process Fundamentals and Mathematical Models. John Wiley \& Sons, Inc., Hoboken, New Jersey.

Binet, P. H., Portal, J. M and Leyval, C., 2000. Fate of polycyclic aromatic hydrocarbons (PAH) in the rhizosphere and mycorrhizosphere of ryegrass // Plant and Soil. - № 227. - P. 207-213.

Blaylock, M., Ensley, B., Salt, D., Kumar, N., Dushenkov, V and Raskin, I., 1995, Phytoremediation: A Novel Strategy for the Removal of Toxic Metals from the Environment Using Plants, Biotechnology, 13 (7), pp.468-474.

Burken, J. G and Schnoor, J. L., 1997, Uptake and Metabolism of Atrazine by Poplar Trees, Environmental Science and Technology, 31, (5): 1399-1406.

Dua, M., Singh, A., Sethunathan, N and Johri, A. K., 2002. Biotechnology and bioremediation: successes and limitations // Applied Microbiology and Biotechnology. - № 59. - P. 143-152.

Dupont, R. R., Doucette, W. J and Hinchee, R, E., 1991. Assessment of in situ bioremediation potential and the application of bioventing at a fuelcontaminated site. In: In Situ Bioreclamation Applications and Investigations for Hydrocarbon and Contaminated Site Remediation, ed. R. E. Hinchee \& R.F. Olfenbuttel. ButterworthHememann. Stoneham, Massachusetts, USA. 262-282.

Federal Ministry of Environment Abuja, Nigerian Conservation Foundation Lagos, WWF UK and CEESP-IUCN Commission on Environmental, Economic, and Social Policy, May 31,(2006). Niger Delta Resource Damage Assessment and Restoration Project.

Graham, L., Hale, C., Maung-Douglass, E., Sempier, S., Swann, L and Wilson, M., 2016. Oil Spill Science: Chemical dispersants and their role in oil spill response. MASGP-15-015.

Hinchee, R. E., Miller, R. N and Dupont, R. R., 1991. Enhanced biodégradation of petroleum hydrocarbons: An air based in situ process. In: Innovative Hazardous Waste Treatment Technologies Series, Volume 3 Biological Processes ed. H. M. Freeman \& P. R. Sferra, Technomic Publishing Co., Lancaster, Pennsylvania, USA. 177-184.

Ireri V Robles-González, Fabio Fava, Héctor M PoggiVaraldo. 2008. A review on slurry bioreactors for bioremediation of soils and sediments. Microbial Cell Factory. 7: 5.

Jing Wang, Yeonjong Koo, Anne Alexander, Yu Yang, Samantha Westerhof, Qingbo Zhang, Jerald L. Schnoor, Vicki L. Colvin, Janet Braam, and Pedro J. J. Alvarez., 2013. Phytostimulation of Poplars and Arabidopsis Exposed to Silver Nanoparticles and $\mathrm{Ag}+$ at Sublethal Concentrations. Environ. Sci. Technol., 47 (10): 5442-5449.

Newman, L. A., Strand, S. E., Choe, N., Duffy, J., Ekuan, G., Ruszaj, M., Shurtleff, B. B., Wilmoth, J., Heilman, P and Gordon, M. P., 1997. Uptake and Biotransformation of Trichloroethylene by Hybrid Poplars, Environmental Science and Technology, 31, (4): 1062-1067.

Raskin, I and Ensley, B. D., 2000. Phytoremediation of Toxic Metals: Using Plants to Clean Up the Environment, Wiley, New York.

Schnoor, J. L., 1997. Phytoremediation, Technology Overview Report, Ground-Water Remediation Technologies Analysis Center, Series E, Vol. 1, October.

Stankevich, D. S., 2002. Using hydrocarbon oxidizing bacteria of the genus Pseudomonas putida for the bioremediation of oil-contaminated soils. Ph.D. Dissertation. - Moscow, 189.

Tyagi, M., da Fonseca, M. R and de Carvalho, C. C. C. R., 2010. Bioaugmentation and biostimulation strategies to improve the effectiveness of bioremediation processes // Biodegradation. - 22 (2). - P. 231241. 
Viatcheslav Dushenkov, P. B. A., Nanda Kumar., Harry

Motto and Ilya Raskin, 1995. Rhizofiltration: the use of plants to remove heavy metals from aqueous streams. Environmental Science and Technology 29(5):1239-45.

Vidali, M. 2001. Bioremediation: An overview // Pure Applied Chemistry. - V. 73 № 7. - P. 11631172. www.science.jrank.org <ahref="http://science.jrank.org/p ages/4848/Oil-Spills-Oil-pollution.html">Oil Spills - Oil Pollution</a> (accessed: 25/04/2017).

US Environmental Protection Agency., 2014. EPA's Toxicity Testing of Dispersants. Retrieved October 10, 2014, from www.epa.gov/bpspill/dispersantstesting.html 